\title{
LA POLÍTICA ECONÓMICA DE ESPAÑA EN LA GUERRA DE LOS 10 AÑOS EN CUBA (1868-1878) ${ }^{\circ}$
}

THE SPAIN ECONOMIC POLICY IN THE 10 YEARS WARS

IN CUBA (1868-1878)

\section{Claudio Gallegos*}

enviado: 11 febrero 2019 - aceptado: 21 agosto 2019

\begin{abstract}
Resumen
Entre los años 1868 y 1878 se desarrolló la primera guerra por la independencia de Cuba sobre su metrópoli España. El desarrollo de exitosas estrategias por parte de los insurrectos provocó una extensión temporal inesperada. En este sentido, este artículo pretende analizar algunas de las medidas económicas llevadas a cabo por el país ibérico vinculadas con el costo de la guerra y el mantenimiento del orden en la isla, las cuales proyectaron cambios en la estructura productiva y social. En concordancia con las acciones de guerra, se divisa una represión socioeconómica. Revisión de presupuestos, mayor emisión de moneda, nuevos impuestos y empréstitos refieren a los puntos a considerar.
\end{abstract}

Palabras clave: Cuba, España, presupuesto, azúcar, política fiscal. Código JEL: N16, N66, N76.

\begin{abstract}
Between the years 1868 and 1878 the first war for the independence of Cuba on its metropolis Spain was developed. The development of successful strategies by the insurgents caused an unexpected temporary extension. In this sense, this article aims to analyze some of the economic measures carried out by the Iberian

Gallegos, C. (2020). La política económica de España en la guerra de los 10 años en Cuba (18681878). Estudios económicos, 37 (75), 107-129.

* IIESS, Departamento de Economía, Universidad Nacional de Sur (UNS)-CONICET. Bahía Blanca, Argentina. Correo electrónico: cgallegos80@gmail.com
\end{abstract}


country linked to the cost of war and the maintenance of order on the island, which projected changes in the productive and social structure. In accordance with the actions of war, a socio-economic repression. Review of budgets, greater issuance of currency, new taxes and loans refer to the points to be considered.

Keywords: Cuba, Spain, budget, sugar, fiscal policy.

JEL Code: N16, N66, N76. 


\section{INTRODUCCIÓN}

Este es un estudio que toma en consideración los aspectos relativos a cuestiones económicas en Cuba durante el conflicto conocido como Guerra de los Diez Años o Guerra Grande (1868-1878). El mismo busca dar cuenta del impacto de la guerra en la producción azucarera, así como también dar a conocer las diversas medidas que llevaron adelante los representantes de España respecto a mantener la economía en momentos de guerra y solventar la misma.

A contramano de los estudios clásicos sobre guerra y economía, en este caso en particular, se afirma que el conflicto bélico colaboró, por un lado, con la evolución evidenciada en la producción de azúcar que abandona el sistema de ingenios y da lugar a la moderna industria azucarera; y por otro lado el tránsito del trabajo esclavo al de tipo asalariado también encuentra un momento crucial en el tiempo que dura la mencionada guerra.

Desde el punto de vista de las finanzas, el inicio de la contienda se condice con la suspensión del sistema tributario de 1867 por medio del decreto fechado en 22 de enero de 1870 concerniente a derechos de aduanas, gravámenes sobre ganadería, recaudación impositiva y emisiones de deuda.

Es por ello que durante los diez años que duró la contienda fueron excesivos los gastos de guerra sumado a los daños que todo tipo de conflicto bélico deja como marca. Tanto la ganadería como la agricultura e incluso la industria sufrieron cuantiosas pérdidas. Por otro lado, las medidas de España tampoco reflejan aciertos destacables. La mayor emisión de papel moneda que tiene como resultado la depreciación con la consecuente suba de precios, no pudo ser controlada por medio de diversos impuestos creados para tal fin.

La caótica situación económica derivó en una constante política de empréstitos de distinta procedencia y con diversas cláusulas que tuvo como consecuencia un incremento sustancial de deuda.

Los lineamientos en materia económica que siguen los diversos representantes de España durante el período que se estudia dan cuenta de una notable represión socioeconómica sobre diversos sectores de la isla. La lucha contra los insurrectos llevó a España a desmejorar la situación de los sectores blancos nacidos en Cuba y también a la clase media. La mayoría de ellos sin ningún vínculo con las fuerzas libertarias, dato no menor ya que se enfrenta a lo relatado por la historiografía existente sobre el tema hasta el momento. 
En el intento de mantener los lazos como metrópoli económica, dañados ya desde antes del inicio de la contienda, las medidas tomadas acentuaron los descontentos con la madre patria, hasta en personas definidas como realistas.

Este estudio, entonces, trata en primer lugar, y de manera breve, el contexto político y militar de los avatares económicos durante la Guerra de los Diez Años en Cuba. A continuación, se analiza en conjunto el desarrollo de la producción azucarera junto al papel del trabajo esclavo. Finalmente se expondrán algunas de las medidas económicas tomadas por España, consideradas las más representativas e impactantes para poder respetar, asimismo, las pautas formales establecidas por esta revista.

Es por ello que se destaca que esta producción forma parte de una investigación mayor acerca de la movilidad forzosa de personas durante dicha guerra. La misma la estoy desarrollando en Columbia University (New York, Estados Unidos) y se vincula con un proyecto de investigación radicado en la Universidad Nacional del Sur (Bahía Blanca, Argentina) denominado “Guerra, Paz y Derechos Humanos interpelados desde la ciencia política y la sociología. Un abordaje trans-disciplinar”.

\section{CONTEXTUALIZACIÓN}

Entre los años 1868 y 1878 fuerzas insurrectas cubanas se enfrentan al ejército español en pos de lograr dos objetivos primordiales: la libertad de Cuba y el fin de la esclavitud. El 10 de octubre de 1868 representa la fecha de inicio por medio del Grito de Yara, aunque es necesario destacar que diversos líderes criollos fracasaron en sus intentos de culminar con las relaciones de tipo coloniales. En una sincronicidad que puede o no asombrar, el 29 de septiembre del mismo año terminaba el reinado de Isabel II por medio de una revolución en España.

Durante una década, un sinfín de estrategias de guerra se desplegaron por la geografía de contienda con el objetivo de doblegar una fuerza por sobre la otra buscando priorizar, entonces, modelos políticos y económicos dispares.

Los conocidos como reformistas bregaban por la obtención de libertades políticas vinculadas con la presencia de representantes en las legislaturas de la metrópoli, quedando latente la idea del paso a la autonomía como inicio de una posible independencia formal. 
Otro de los puntos sobre los que insistían lo representaba la supresión de la administración de aduanas, debido a que la diversidad de impuestos al comercio y a la importación favorecía solo intereses de España, restando capacidad de negociación con otras naciones. Al respecto resulta interesante ver la recepción por parte de España de tal pedido:

Los verdaderos conservadores hoy retraídos y los hombres de corazón nacidos en la Península ó en Cuba: las Autoridades y las clases productoras todas, deben saber que hoy como ántes de estallar la insurrección de Yara, los que hablan de la necesidad de establecer el libre cambio suprimiendo las Aduanas; que son casi la única fuente de recursos permanentes y sólidos que puede tener el Gobierno, lo que quieren es que desaparezcan los derechos diferenciales de procedencia y de bandera; lo que traducido al lenguaje vulgar que saben tergiversar los regeneradores cómo y cuándo les conviene, quiere decir: QUE SE IMPONGAN Á TODOS LOS EFECTOS DE PRODUCCION ESPAÑOLA QUE SE IMPORTEN EN CUBA EN BANDERA ESPAÑOLA, LOS MISMOS DERECHOS QUE PAGUEN LOS ARTÍCULOS DE PRODUCCIÓN EXTRANJERA QUE SE IMPORTEN CON BANDERA EXTRANJERA (Gelpi y Ferro, 1879, p. 15) ${ }^{1}$.

La esclavitud era el tema que generaba divisiones hacia el interior. Mientras estaban quienes sostenían la gradual abolición de la misma (algunos también llegaron a plantear que sea inmediata), otros, y sobre todo los comerciantes poseedores de esclavos, planteaban continuar con los debates para este tema que no refería a ser resuelto de manera satisfactoria para todos (Varela, 1944, 183). Al momento de iniciada la contienda, independencia y libertad eran las banderas a enarbolar.

Por otro lado, los representantes de España en Cuba consideraban que una reforma en el régimen colonial tradicional sería muy peligrosa y que, asimismo, beneficiaría a otras naciones como Estados Unidos, provocando una desconexión del manejo del comercio de la más importante producción de azúcar en el momento.

Ya para 1868, y más aún en el año siguiente, los insurrectos se encontraban en tres zonas bien delineadas. Por un lado, en el inicio de las contiendas se ubicaban al suroeste de las provincias orientales, entre las que se destacaban Manzanillo, Bayamo y Jiguaní. En lo concerniente a la zona occidental la insurrección lograba bases en la región de Camagüey. Por último, la tercera zona de influencia al inicio

1 Las mayúsculas son del original. 
de los enfrentamientos la representaba Santa Clara, conocida también como Cinco Villas (Cayuela Fernández, 1998, p. 249)².

En contrapartida, ciudades importantes del oriente cubano quedaron bajo el domino de fuerzas españolas tales como Santiago, y de occidente conservaron $\mathrm{La}$ Habana y Pinar del Río (Guerra, 1952, pp. 7-25).

Figura 1. "Isla de Cuba con arreglo a la nueva división territorial”. "Antillas Españolas”

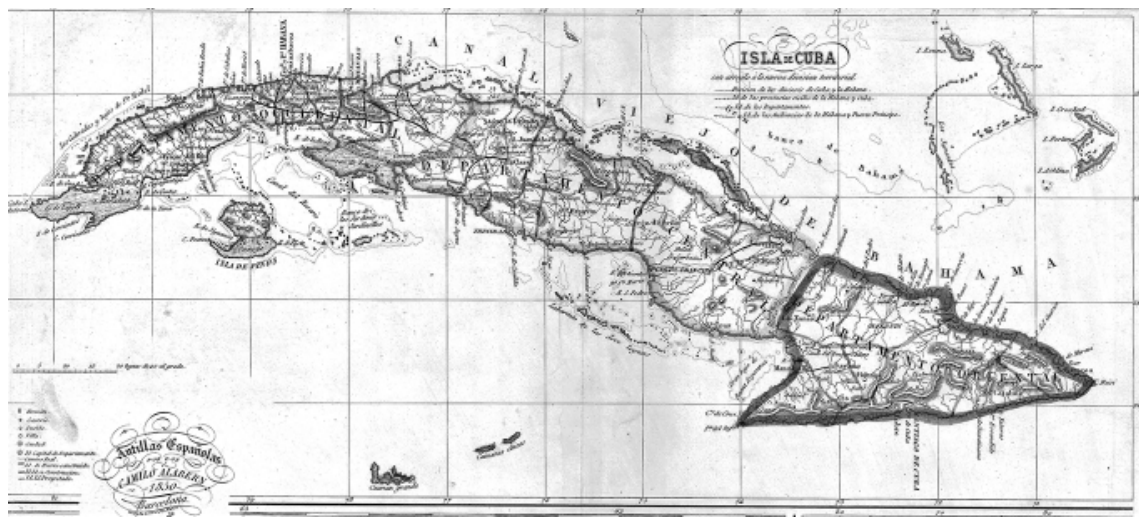

Fuente: Camilo Albern, 1850. Disponible en http://cartotecadigital.icgc.cat/cdm/singleitem/ collection/america/id/559/rec/20

En términos generales la insurrección logró mantener sus territorios sobre la zona central y oriental de Cuba desde el Grito de Yara a la Paz del Zanjón. Para ello fue necesario el diseño de estrategias para combatir contra un ejército profesional, mejor armado y preparado. Las fuerzas independentistas en muchas ocasiones tuvieron que optar más por la defensa que por el ataque.

Ahora bien, el logro de la resistencia insurgente puede comprenderse, en parte, en torno a las decisiones que llevaron adelante los españoles en lo

2 Las regiones de occidente concentraban el 80\% de la población y el 90\% de la riqueza azucarera. En este contexto, los hacendados preferían evitar cualquier tipo de conflicto con España. Por otro lado, en las regiones orientales había menos ingenios azucareros y esclavos. Si a esto le sumamos que las comunicaciones se habían determinado en función de la industria del azúcar queda claro que la zona oriental era más extensa y menos desarrollada, lo que provocó un inconveniente para el despliegue de las tropas españolas, favoreciendo a los insurrectos en el control de las mismas (Aguilar, 1992, p. 212). 
concerniente a políticas represivas contra la población cubana. La deportación, la movilidad de poblados enteros a nuevas zonas desprovistas de bienes para la subsistencia, la encarcelación, los embargos y la emigración forzosa fuera de la isla fueron solo algunas de esas drásticas medidas que dejan como saldo una significativa reestructuración de la sociedad cubana.

El insistente accionar sobre la población civil como estrategia de guerra para debilitar las fuerzas insurrectas determinó por un lado la presencia de las mismas por una década, y por otro lado la realización de un elevado número de crímenes y vejámenes ${ }^{3}$. Fue necesaria una gran cantidad de tropas españolas destinadas al cumplimiento de embargos, deportaciones, etc., descuidando en algunos momentos la lucha armada.

En este contexto, el ejército cubano apeló a enfrentamientos sorpresa, pudiendo obtener la victoria, unida a la confiscación de armamentos y bienes para la subsistencia, por ejemplo.

Sin embargo, una serie de derrotas por parte de las tropas peninsulares en concordancia con desavenencias internas en las tropas insurrectas por cuestiones políticas de dirección de la República de Cuba en Armas $^{4}$ condujeron a la firma de un acuerdo entre las partes para poder lograr la paz.

Luego de casi 10 años de lucha, las fuerzas revolucionarias daban cuenta de una gran escases de recursos, la descoordinación con respecto a la ayuda proveniente del exterior, la crisis política al interior de sus fuerzas y las presiones de Estados Unidos preocupados en mantener el comercio azucarero de forma preponderante.

Acto seguido se firma el conocido como Pacto del Zanjón en medio de grandes diferencias ${ }^{5}$ por considerar a dicho acuerdo como la claudicación de los ideales libertarios. Un nuevo momento comenzaba para 1878.

3 Las consecuencias demográficas de las políticas españolas en Cuba durante la Guerra de los Diez Años dan los siguientes números: entre 30000 y 100000 cubanos que migran de manera forzosa, sumado a 200000 víctimas producto del resto de las medidas.

4 Refería un inconveniente la sucesión de presidentes en la naciente República de Cuba en Armas.

5 El mismo es rubricado por el representante de España en Cuba, general Arsenio Martínez Campos y varios generales cubanos. Sin embargo, un número considerable de cubanos libertarios lo ven como una claudicación en los ideales propagados por medio de diez años ininterrumpidos de lucha. 


\section{AZÚCAR Y ESCLAVITUD}

En los albores de la primera lucha por la independencia en Cuba, esta colonia, caracterizada como la más rica y poblada de España, enfrentaba una serie de inconvenientes en materia económica y política. El punto clave lo representaba la producción de azúcar en la isla. Si bien mantenía niveles considerables de producción, e incluso mejorando valores en lo concerniente a la exportación, las nuevas competencias planteaban un gran desafío. Es dable mencionar al respecto el importante papel que va logrando el azúcar de remolacha tanto en Europa como en Estados Unidos, sumado a la explotación de nuevas zonas cañaverales, lo cual planteaba preocupaciones a futuro.

Para el inicio de la Guerra de los Diez Años (1868-1878) la modernización de la producción de azúcar era un hecho. La mecanización de la producción necesitaba de un cambio en el sistema arcaico implantado desde la colonia en materia comercial ${ }^{6}$. Las evidencias dan cuenta del quiebre que esto representa dando lugar a nuevas metrópolis económicas para Cuba en un momento en el cual aún España representaba su metrópoli político-administrativa.

Para la misma fecha otro tema a considerar lo representa el papel de la esclavitud en el entramado sistema económico de la isla. Engranaje principal de la producción azucarera. Según el tratado que firman España y Gran Bretaña en el año 1817, la trata de esclavos sobre la zona de Cuba era ilegal, situación que de todos modos se mantuvo hasta 1835, cuando los controles se hicieron más estrictos.

Es por ello que ya desde medidos de la década del sesenta del siglo XIX, gran parte de la elite económica de Cuba se concentraba en lograr reformas en el comercio unidas a la abolición gradual de la esclavitud con compensación de pérdidas. Por el lado de España, cualquier cambio ayudaba a la independencia de la isla ${ }^{7}$.

Cuba poseía una serie de ventajas desde lo climático y geográfico con respecto al resto de las colonias españolas en cuanto al desarrollo de la industria

6 Paradójicamente, la insurrección comienza en un pequeño ingenio azucarero conocido como La Demajuaga.

7 La oposición a España iba en aumento, entre otras cuestiones, por la gran cantidad de impuestos considerados altos e injustos. Un dato no menor, y como destaca Luis Aguilar (1992), Cuba financió la expedición española en México en el año 1862 junto a otras campañas en África, Perú y Chile (p. 211). 
azucarera $^{8}$. Asimismo, contaba con la necesaria dotación de recursos humanos para tal caso, dando lugar a las inversiones.

Ya desde mediados del siglo XIX, la producción de los derivados del azúcar demostraba importantes crecimientos ${ }^{9}$. Incluso hasta 1870 Cuba fue la primera exportadora de azúcar en el mundo. Para ello resulta pertinente comprender un período que se extiende entre 1860 y 1880, dentro del cual se desarrolla el conflicto bélico independentista.

8 Destaca Moreno Fraginals (2001), cuatro aspectos primordiales en la isla para la manufactura azucarera “... primero tierras fértiles, de fácil explotación situadas cerca de la costa, con fácil acceso a los puertos de embarque; segundo bosques que proporcionasen maderas de gran calidad para la construcción de trapiches, carretas e implementos, y para levantar el conjunto de edificios requeridos, aparte de suministrar combustible (leña) durante toda la zafra; tercero ganado abundante que alimentase a los esclavos y tirase del trapiche y las caretas (...); cuarto instrumentos de trabajo” (p. 9).

9 En especial mieles, ron, etc. 


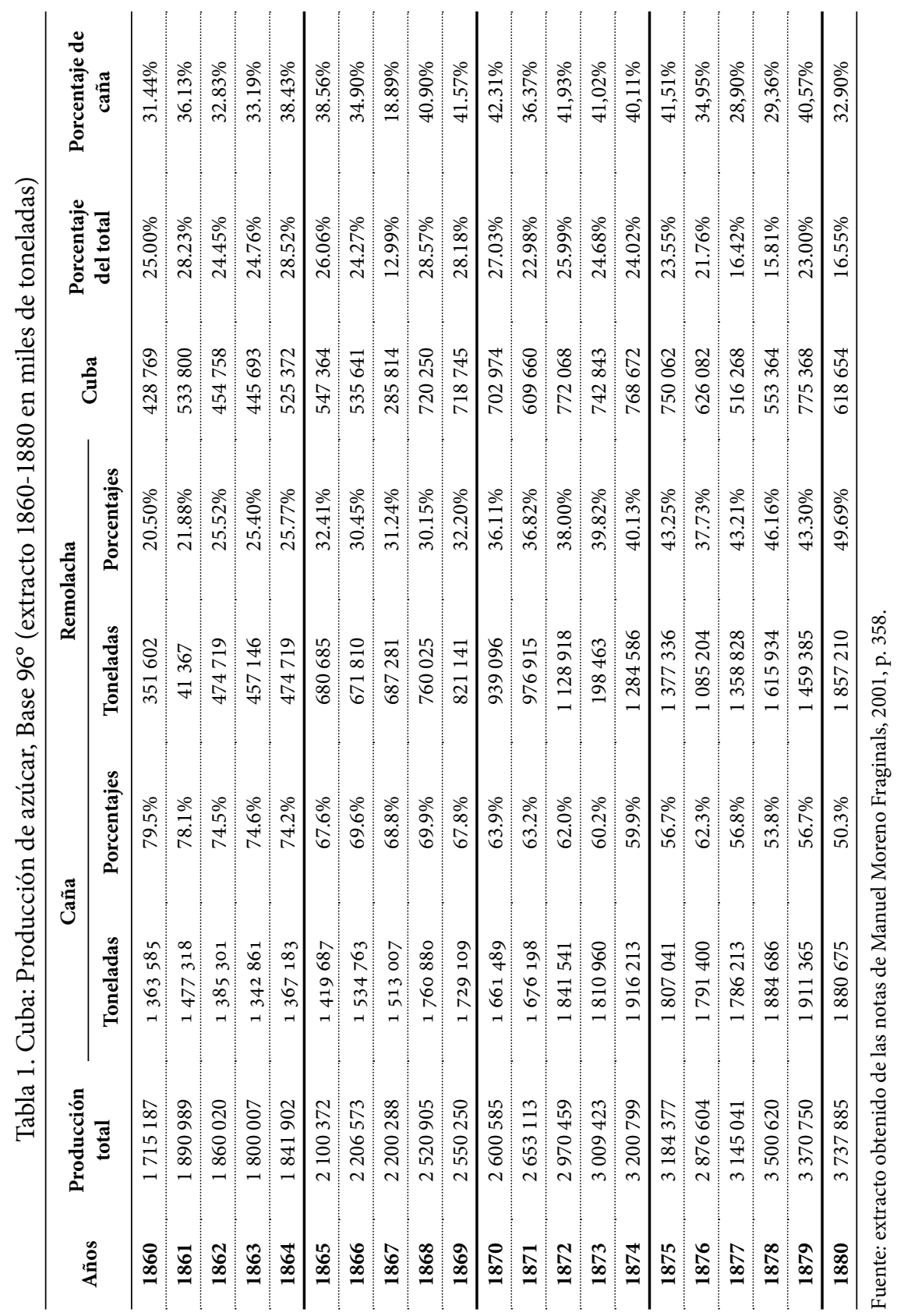


Durante el período delimitado, la industria del azúcar atraviesa transformaciones fundamentales. Comienzan nuevos modos de producción y comercio que da como resultados cambios en el producto final. Las nuevas normas de producción otorgan incluso modificaciones en la presentación.

Incluso, la guerra deja como resultado la aparición o mejoramiento de las condiciones de los comerciantes quienes se ven favorecidos por el comercio internacional o por suministrar productos a las fuerzas realistas.

Continúan persistiendo, mientras tanto, construcciones edilicias añejas, que comienzan a tener un uso social más que de producción. Se preservan las rutas comerciales establecidas por el tendido de las vías férreas y los campos cañaverales. Estos últimos experimentan una ampliación con relación a los de los antiguos ingenios. En los dos decenios seleccionados, el paso de estos a las conocidas como centrales azucareras fue posible, también, por el acceso a mayor cantidad de tierras fértiles a bajos $\operatorname{costos}^{10}$.

Es necesario destacar que la evolución de la industria azucarera no estuvo acompañada por una revolución en el resto del sector agropecuario. El trabajo en el campo continuaba, en un primer momento, ligado a la posesión de esclavos más allá de los cambios en el ámbito jurídico.

Asimismo, la Guerra de los Diez Años se encuentra muy cercana a la fase de globalización que vive la economía entre 1870 y 1913, caracterizada por la movilidad de capitales y fuerza de trabajo sumado a la expansión comercial. Todas características de la producción azucarera en la periodización presentada para este estudio.

Entre los años 1868 y 1878, más allá del pánico que generaba la guerra en lo concerniente al comercio internacional del azúcar, se verifican excelentes cosechas a precios altos ${ }^{11}$. La evolución hacia las centrales observa en esas fechas sus mejores resultados, retornando a una nueva crisis posteriormente.

10 De los 1318 ingenios de azúcar que existían para 1860 solo quedan 250 para 1895 . En contrapartida, el nivel en toneladas de azúcar se duplica.

11 El efecto distorsionador de los mercados se sentía desde la Guerra de Secesión en Estados Unidos (1861-1865). Es necesario recordar también otro conflicto externo importante durante el período seleccionado como es la guerra franco-prusiana (1870-1871). 
Es interesante recordar algunas cifras. Entre 1858 y 1868 se produjeron 5496706 toneladas de azúcar; mientras entre 1869 y 1878 alcanzó la cifra de 6817361 toneladas (Ibarra, 2008, p. 263).

En este sentido, es posible afirmar que la Guerra de los Diez Años fue rentable para la industria del azúcar. Justifica dicha afirmación el hecho de que la mayoría de los enfrentamientos bélicos se dieron sobre el oriente de la isla, destruyendo la mayoría de los ingenios, caracterizados por su atraso tecnológico y sus escazas producciones. En contrapartida, el occidente de la isla logra desarrollar sus centrales azucareros llegando a producir el 80\% del total de azúcar en Cuba.

De todas formas, la industrialización del azúcar no impactó en el progreso político ni en la modernización social. Ya desde mediados del siglo XIX, La Habana, por ejemplo, era una gran ciudad cosmopolita con un $61 \%$ de negros. De ellos, solo el 13\% refería a habitantes urbanos libres.

Uno de los puntales necesarios para el desarrollo del azúcar manufacturado se relaciona con la esclavitud. Durante el período seleccionado, dicho término refiere a una considerable diversidad de explotación de mano de obra.

Según Moreno Fraginals, la clasificación era la siguiente:

1. esclavo puro: persona que estaba obligada a trabajar en el ingenio;

2. esclavo contratado: no podían recaer sobre él castigos físicos y recibía una remuneración por su servicio;

3. esclavo jornalero: percibía un salario por su trabajo en el ingenio y parte del mismo era entregado al contratante por su calidad de semiliberto;

4. esclavo asalariado: era una modalidad muy común en la época. Dicho esclavo cobraba entre el 50\% y el $70 \%$ del salario de un hombre libre. Asimismo, gozaba, generalmente, de una pequeña porción de tierra para su usufructo (1991, p. 179).

Estos trabajadores no se encontraban solos. Fue usual en su momento la presencia de trabajadores blancos libres junto a chinos. Asimismo, los presos de guerra fueron puestos a trabajar en los ingenios. Estos también percibieron un pequeño salario.

Esta gran oferta de mano de obra, ligada a la esclavitud en todas sus formas, era el causante del retraso del desarrollo industrial capitalista en lo concerniente al 
azúcar. Así, la abolición de la esclavitud buscaba racionalizar el sistema precario de mano de obra imperante. Y este pedido fue una de las banderas que la insurrección levantó para llevar a cabo la guerra.

Como parte de sus medidas de dejar sin recursos a los insurrectos, el gobierno español llevó adelante una política de embargos de bienes. Entre los mimos se encontraron los esclavos, razón por la cual un gran número dejó de ser parte del patrimonio personal de las personas y pasaron a la esfera estatal.

Los esclavos embargados atravesaron un proceso de desplazamiento geográfico, en calidad de arrendamiento, hacia el occidente de la isla, bajo nuevos mecanismos de fiscalización de los mismos, y con la tarea de reforzar el aumento de demanda evidenciado desde el exterior.

Debido al alto número de reconcentración de mano de obra esclava en la zona occidental, fue necesaria la reapertura de nuevos lugares para el desarrollo de sus tareas (cárceles, por ejemplo).

Estos cambios generaron profundas transformaciones en la sociedad cubana, en particular en la clase alta. Muchos de los ricos propietarios y hacendados azucareros se vieron perjudicados por el conflicto perdiendo bienes y tierras, mientras que otros, por las diversas medidas económicas de tipo represivo, atravesaron la misma situación. La más recordada de todas las medidas la representa el embargo.

Dichos propietarios, en general, se vieron en la obligación de vender sus posesiones arruinadas por la guerra y fue recurrente la aparición de capitales norteamericanos para la compra de las mismas, a precios muy bajos, aumentando de esta forma la penetración económica de Estados Unidos en Cuba.

Asimismo, la intensa actividad económica vinculada a la industria azucarera dejó más consecuencias en la naturaleza de la isla que las acciones bélicas. La preponderancia de la madera como combustible de las centrales se acrecentaba luego de las zafras, dando como resultado la disminución de los bosques.

La vinculación entre la producción azucarera y la esclavitud, entonces, es clave durante el desarrollo de la Guerra de los Diez Años. No solo porque, como se comentó anteriormente, se asiste a la destrucción de una gran cantidad de ingenios, sobre todo en la zona oriental, dando espacio en las provincias de esa zona a la 
posibilidad de modernizar la industria azucarera ${ }^{12}$, sino que además la corrupción en la administración de la isla permitió la realización de un comercio transatlántico de esclavos, dando lugar a un mercado ilegal de compra y venta de personas. Luego de culminada la guerra, entonces, dicho tráfico fue la base de enormes riquezas.

\section{ECONOMÍA EN TIEMPOS DE GUERRA}

Como bien comenta Inés Roldán en una de sus excelentes investigaciones titulada La Hacienda en Cuba durante la Guerra de los Diez Años (1868-1878), es necesario considerar que para el inicio de la insurrección existía en la isla un presupuesto aprobado con anterioridad, en donde no se contemplaban gastos por conflictos bélicos (1990, p. 139).

Revisando los añejos papeles de Mariano Cancio Villaamil ${ }^{13}$ es posible observar que para el período comprendido entre junio de 1868 y junio de 1869 los ingresos se habían calculado en un total 31114662 pesos sobre 25415945 pesos de gastos. Para octubre de 1868 estalla la guerra y para los cuatro períodos siguientes que van de 1869 a 1873, el presupuesto se rigió por ampliaciones, las cuales no se encuentran especificadas (Villaamil, 1883, pp. 29-30). En las figuras 2 y 3 pueden verse el detalle de los presupuestos para el período que se estudia.

Para el presupuesto extraordinario del período 1870-1871 fue aprobado el Proyecto de Sigismundo Moret por decreto de Serrano el 12 de octubre de 1870. Para saldar el déficit de presupuesto 1870-1871 y cubrir atenciones especiales de guerra se autoriza al ministro de Ultramar, Víctor Balaguer, que haga uso de los fondos del Tesoro de Cuba proveniente de créditos. El ejercicio correspondiente a 1874-1875 fue aprobado en junio de 1875 y prorrogado por Reales Ordenes hasta 1877-1878 en base al proyecto de Cancio Villaamil.

12 Los daños fueron menores y el proceso evidenció un aceleramiento considerable. De todas formas, permanecen intactos los retrasados patrones agrícolas.

13 Político español que no solo formó parte de las Cortes de España sino que, además, fue comisionado por el Banco Colonial Hispano entre 1876 y 1878. 
Figura 2. Presupuesto de ingresos y gastos de la isla de Cuba (1860-1880) n GASTOS Pesos fuertes INGRESOS Pesos fuertes

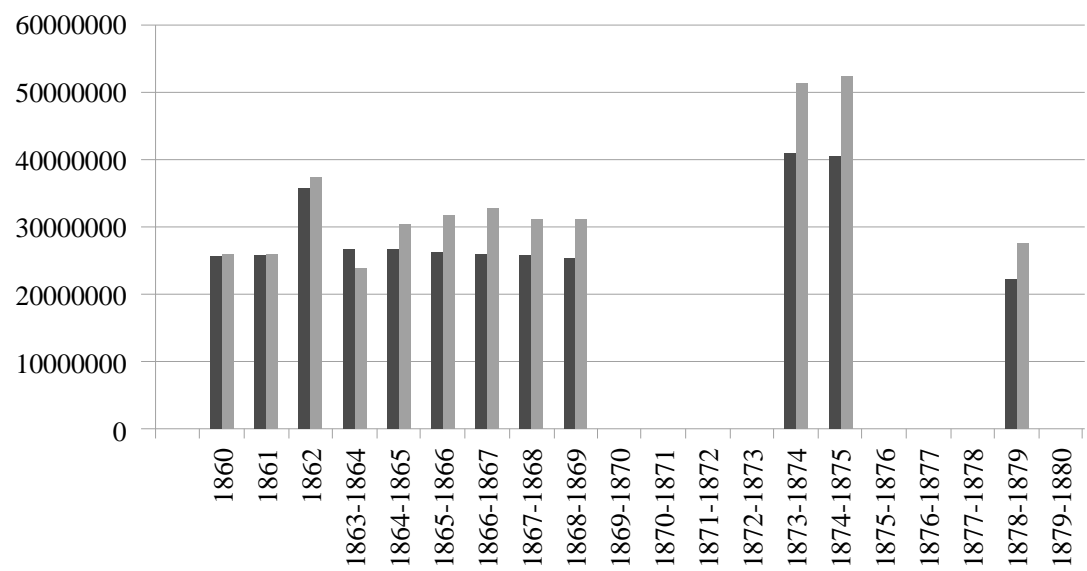

Fuente: elaboración propia sobre la base de extracto obtenido de Mariano Cancio Villaamil, pp. 29-30.

Figura 3. Presupuesto extraordinario de ingresos y gastos de la isla de Cuba (1870-1871)

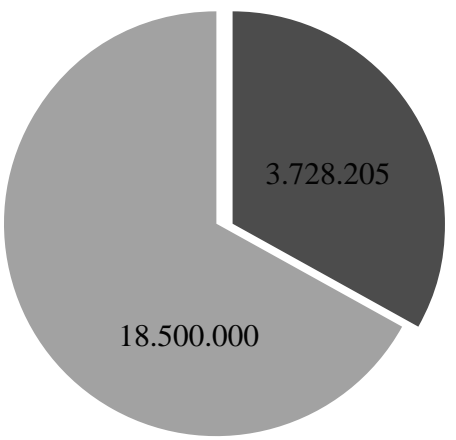

GASTOS INGRESOS

Fuente: elaboración propia sobre la base de datos extraídos de Emilio Augusto Soulere, pp. 715-716.

Como se expuso al principio de este artículo, la reina Isabel II había sido destronada. Para octubre de 1869 ejercía las funciones de Gobierno la Junta Provisional Revolucionaria de Madrid que, en febrero de 1869, nombra como presidente del Poder Ejecutivo a Francisco Serrano y Domínguez. En ese contexto es enviado a Cuba el general Domingo Dulce como capitán general. 
El mencionado militar arriba a la isla con una serie de reformas económicas tendientes a culminar con la insurrección y, en paralelo, solventar los enfrentamientos necesarios para tal fin.

Es necesario mencionar nuevamente que, luego del inicio de las acciones insurrectas sobre la zona de Yara y por decreto del 22 de enero de 1870, se suspende el sistema tributario de 1867. De esta manera, se restituyen las condiciones pautadas hasta antes de esas fechas entre las que se destacan el restablecimiento de los derechos de exportación junto a los gravámenes de la ganadería.

La nueva realidad da cuenta de una suba en el déficit desde años anteriores a la lucha que en el transcurso de los meses se va incrementando de manera vertiginosa a punto tal que las decisiones de España no ayudaban: creación de más impuestos y emisión de deuda.

Ante la necesidad de dinero para afrontar los gastos bélicos se acudió a la mayor emisión de papel moneda. La limitación establecida para tal caso fue que el límite no podía exceder el triple del capital existente y, asimismo, un tercio de dicha emisión debía estar respaldada por reservas en metal (López Oto, 1970, p. 410).

Para que se efectivizara dicha media, el flamante capitán Dulce creó una comisión para su tratamiento que daría sus resultados al Banco Español de la Habana. El resultado final fue la emisión de hasta 8000000 de pesos en billete, entregados en distintas etapas ${ }^{14}$.

Sin embargo, ya para junio del mismo año, el nuevo gobernador Caballero de Rodas ${ }^{15}$ acude a la Comisión solicitando 6000000 de pesos más por el déficit real existente. La comisión aprueba la nueva emisión. La deuda con el banco de a poco se iba incrementando.

Los movimientos de tropas españolas a la isla para culminar con la insurrección fue uno de los puntos esenciales para el endeudamiento en todo el transcurso de la guerra. Los distintos gobernadores de Cuba acudían con asiduidad

14 Los detalles sobre este tema en particular, incluidos en el Decreto aprobado por el Gobierno provisional el 27 de abril de 1869, fue publicado con anterioridad en la Gaceta de la Habana el 23 de febrero de 1869.

15 Dulce padecía una enfermedad terminal que lo alejó de sus funciones hasta morir en ese mismo 1869. 
a la mencionada comisión pidiendo más emisiones aludiendo diversas garantías para tal caso ${ }^{16}$.

Para el año 1871 la realeza recupera el trono y junto al nuevo Rey Amadeo I la política de emisión continúa intacta. Solo en el año signado con anterioridad, debido a los excesos en la emisión, la suma no amortizada rondaba los 34000000 de pesos (López Oto, 1970, p. 413) ${ }^{17}$.

Para el año 1872 el importe total de las emisiones de dinero desde comenzada la guerra era de 47000000 de pesos. Dos años más tarde, la suma superaba los 62000000 de pesos ${ }^{18}$.

Esta desesperante masa de billetes circulando por la isla representaba una gran bomba de tiempo. Por ello fue necesaria una fuerte política fiscal que tenga la fuerza de poder retirar de circulación las emisiones realizadas extraordinariamente sin dejar graves consecuencias en la complicada economía insular.

En función de lo antes dicho, la emisión de nuevos impuestos, sumado a diversas modificaciones sobre los ya existentes tenía un doble objetivo: obtener dinero y lograr solventar la guerra.

En tiempos complejos, como es comprensible en medio de enfrentamientos bélicos, la población se mostró, en general, reacia a las medidas en materia fiscal. En función de las pautas de la revista en la que se encuentra este artículo se hará alusión solamente a los hechos más importantes en materia tributaria.

Sumado al decreto efectivizado por Dulce, y ya comentado en páginas anteriores, es necesario considerar otros. Uno de ellos lo representa el aumento del 5\% sobre los haberes percibidos por el Estado. Este impuesto se extendió desde marzo de 1869 hasta marzo de $1875^{19}$.

16 En estos últimos casos se apela como garantía no solo con el producto de los bienes embargados, sino también con la totalidad del capital.

17 En general se emitían una gran cantidad de billetes de uno y tres pesos con la idea de poder obtenerlos con facilidad en el momento de normalización de la moneda.

18 Las estimaciones se realizan en base a los datos aportados por José de Granda en su obra Reflexiones sobre la insurrección de Cuba publicado en 1876

19 Como fue usual en lo que respecta a la publicación de los decretos, el citado en el cuerpo del trabajo también puede ser consultado en la Gaceta de Madrid del 23 de marzo de 1875, momento en el cual el impuesto pierde vigencia. 
Otra de las imposiciones de la época duró entre febrero de 1869 y abril de 1871. El decreto pertinente estableció un recargo del 10\% sobre las tarifas de importación, sumado a un impuesto de 7 escudos por cabeza de ganado mayor, 2 escudos por cada ganado menor y un recargo del 5\% sobre productos líquidos (López Oto, 1970, p. 418).

Tras el abandono de Dulce en su cargo, Gutiérrez de la Concha continuó con su política fiscal. Impuso un $10 \%$ de aumento sobre las utilidades buscando el regreso de billetes al Tesoro y, asimismo, logró pactar con los hacendados un tributo por el período de dos años de $2.5 \%$ sobre el valor real de cada una de las propiedades.

Para 1875 llega a Cuba el Conde de Valmaseda. El nuevo representante de España en la isla trae consigo un nuevo plan de reformas entre las que se destacan culminar con el pacto logrado por Gutiérrez de la Concha.

Los ingresos de dicho impuesto son suplantados por otros, entre los que se destaca un aumento el 5\% en oro sobre las utilidades (llegando entonces al 15\%). Si bien el aumento anterior a las utilidades tuvo como finalidad la amortización de los billetes, en este nuevo caso se cubriría con "la venta en pública licitación y sin tipo fijo, de 500.000 pesos mensuales en Bonos del Tesoro de la emisión de 1872, conservados en cartera con un interés del 8\%” (López Oto, 1970, p. 419).

Junto a las medidas comentadas anteriormente, ligadas al papel moneda y al sistema tributario, es necesario resaltar también el enfrentamiento ideológico que por aquel momento enfrentaba al mercantilismo y la fisiocracia. Los planes de continuar con un proteccionismo o afrontar el librecambio ponía en discusión, por un lado, las ansias libertarias pero, por otro lado, la posibilidad de intromisiones de nuevas potencias.

Para el inicio de la guerra queda sin efecto la diferencia de aranceles para mercaderías provenientes de distintos países ${ }^{20}$. Pero hacia finales de 1874 se produce la Restauración de los Borbones en España, con la consecuente desaparición de su Primera República. A partir de este momento se retoma el proteccionismo tan criticado por la insurrección. Por medio de dicha medida se buscaba una mejora en la producción del azúcar, pero sobre todo en el comercio de la misma.

20 Se suprime, entonces el mencionado decreto del 12 de marzo de 1867 en donde se imponían tarifas proteccionistas para el comercio de la isla con España en detrimento de otras naciones. 
De todas formas es necesario volver a recordar que la mayor concentración de producción de azúcar se encontraba en el occidente de la isla, zona de pocos enfrentamientos con la insurrección. En otras palabras, la guerra no influyó de manera directa en este punto aunque la medida mencionada buscaba solventar el conflicto bélico.

Otra de las formas de afrontar los gastos de guerra se relaciona con la política de empréstitos. A lo largo de toda la contienda se evidenciaba que las medidas monetarias y las políticas fiscales no eran suficientes para mantener tan cuantiosa situación.

Es necesario aclarar que entre Cuba y España no existía una unidad de Tesoros. Ambas administraciones políticas poseían realidades económicas diferentes y por lo tanto distintos Tesoros. El de la isla se caracterizaba por su propio presupuesto mientras que en España existía una Hacienda central junto a un presupuesto general de Estado. Las órdenes tributarias también diferían entre colonia y metrópoli (Roldán, 1997, p. 36).

En reiteradas oportunidades el Tesoro de la isla fue el motor de sustento para distintas acciones bélicas de la metrópoli en el resto del continente americano. Pero para el caso de la guerra en Cuba, como se mencionó con anterioridad, los gastos provendrían de la isla.

Ante la incapacidad de Cuba de poder solventar por si sola los costos de la guerra, diversos préstamos fueron concretados, entonces, entre el Tesoro central y el propio de La Habana ${ }^{21}$. El primero de ellos se firma a solo dos meses de iniciada la guerra por un valor de 1000000 de pesos. La recuperación del mismo se realizaba por medio de las contribuciones en la isla. Con el paso de los años la política de embargo será una herramienta crucial para poder saldar los empréstitos. Gracias a ello es que en años siguientes se accede a nuevos préstamos por valores de 2000000 y 895480 pesos cada uno.

Para 1870, según López Oto, se logra un nuevo préstamo por un valor de 1000000 de pesos con un interés del 6\% (1970, p. 425). Dicho autor da cuenta de negocios entre España y banqueros extranjeros en pos de lograr ayuda para solventar la guerra. Mientras tanto, la deuda no se saldaba en su totalidad.

21 También se concretaron diversos empréstitos con entidades extranjeras. 
Para dar por terminada la guerra, entonces, se da rienda suelta a la política de empréstitos y mayor deuda pública. Precisamente, el historiador y político español Antonio Pirala comenta, en su indispensable obra sobre la temática en cuestión Anales de la Guerra de Cuba, que desde Madrid partió la orden para que se librara contra el Tesoro español un préstamo de 50000 pesos diarios que serían contabilizados como parte del presupuesto extraordinario de guerra22.

Para 1876 un grupo de financieros españoles anticipan un total de 25000000 de pesos que tenía como garantía la renta de aduanas de la isla. El interés pautado fue de un 12\% (Roldán, 1990, pp. 185-207).

Tema aparte lo representa el coste final de la guerra. En otras palabras, el viaje de regreso de las tropas, por ejemplo. Para ello también fue necesario un nuevo empréstito realizado por el general Arsenio Martínez Campos con un valor de 25000000 de pesos. Dicho empréstito, que fue recibido por el Tesoro de Cuba, estaba garantizado por medio de rentas de aduanas y en gran medida el dinero provenía de capitales ingleses y franceses.

Muchos fueron los números consultados en cuanto al presupuesto final de guerra. La diferencia entre los mismos los vuelve cuestionables por lo que se ha decidido no ponerlos en cuestión. De todas formas, la crítica situación que debía afrontar España luego del Pacto del Zanjón referenciaba más medidas estrictas que recaerían sobre la población insular ${ }^{23}$.

\section{CONCLUSIONES}

La Guerra de los Diez Años debe ser comprendida desde su contexto internacional e interno. Iniciando la década de 1860 varias revueltas se suscitaron sobre el continente. La Guerra de Secesión Norteamericana más la invasión a México por parte de Francia, Inglaterra y España, sumado a la Guerra en República Dominicana promovieron, de alguna manera, el activismo independentista en Cuba.

Hacia el interior de la isla, las delimitaciones geográficas y sociales dieron cuenta de diversos enfrentamientos. Sobre la zona oriental la presencia de añejos

22 Se recomienda la lectura de los tres tomos de la mencionada obra publicada entre 1895 y 1898.

23 Resulta pertinente revisar la citada obra de Pirala así como también la de Francisco Camps y Feliú de 1890 denominada Españoles e insurrectos. Recuerdos de la guerra en Cuba, y el texto de Emilio Augusto Soulere, Historia de la insurrección en Cuba, publicado en 1879. 
ingenios azucareros y factorías de tabaco dependientes de la mano de obra esclava contrasta con un occidente en vías de modernización. Independencia y autonomía representa cada una de esas zonas respectivamente.

En este contexto comienzan las luchas por la liberación. El mismo que observa España para desplegar sus estrategias tendientes a culminar con la insurrección. Es en este marco en el que es necesario comprender las medidas económicas efectivizadas.

La sociedad en general sufría la cotidianeidad de las diversas medidas desarrolladas por España, entre las que se destaca la inflación y consecuente aumento de precios, punto mencionado en el cuerpo de este trabajo. En lo que respecta a la esclavitud durante la guerra, por un lado, se dio curso a la ley de libre vientre ni bien comenzada la contienda junto a su extensión posterior a esclavos mayores de 60 años. Pero, por otro lado, la verdadera abolición de la esclavitud, bandera esencial de los insurrectos, se logra en Cuba luego de la guerra que se estudia. Recién en 1880 se consigue tal objetivo.

También se divisan modificaciones en cuanto a la relación con la naturaleza. Hasta iniciada la guerra, esta relación tenía como eje la utilidad. Las zonas pobladas remitían a fértiles campos para la caña de azúcar o diversos lugares cercanos a fuentes naturales de agua para la producción de tabaco.

El sistema fiscal también sufrió modificaciones en tiempos de guerra. No solo fue necesaria la creación de un subsidio extraordinario de guerra con el objetivo de complementar la emisión de billetes sino que también se establecieron aranceles específicos a lo largo de los diez años de contienda.

En lo concerniente al presupuesto de ingresos se pudo demostrar que los mismos aumentaron en más de 20000000 de pesos como resultado de la mencionada creación de impuestos o modificación de los existentes. De todas formas, la guerra se presentaba como una voraz consumidora de recursos a punto tal de poseer ya para 1871 un descubierto de 60000000 de pesos.

También se llevó adelante una política de empréstitos tempranamente al observar que los medios financieros de la propia isla no alcanzaban para afrontar todos los costos de guerra. 
Tanto la Primera República Española como el reinado de los Borbones durante la Guerra de los Diez Años demostraron la incapacidad de poder calcular de manera exitosa el verdadero coste de la guerra. En este contexto se dedicaron a emitir deuda en forma de billete, por medio de créditos o por el incumpliendo en el pago de los compromisos asumidos.

Es por ello que, finalizada la guerra, la deuda creada intenta ser afrontada contrayendo más deuda con el capital financiero exterior. En este nuevo panorama los acreedores demuestran sus intereses de perpetuar el orden colonial intentando ser parte protagonista.

Ejemplo de ello lo refiere que entre la finalización de la Guerra de los Diez Años en 1878 y el inicio de una nueva contienda en 1895 no se construyeron nuevas vías férreas, ni hubo mantenimiento sobre caminos, los cuales se vieron deteriorados, y tampoco se construyeron colegios basados en la idea de que allí se impartían ideales independentistas.

Todas las medidas llevadas a cabo durante la contienda por parte de España tuvieron como base la perpetuidad del orden colonial. El mismo pudo ser conservado hasta 1898, donde la independencia tutelada de Cuba bajo Estados Unidos abre la puerta a una nueva época, la de la neocolonia.

\section{REFERENCIAS BIBLIOGRÁFICAS}

Aguilar, L (1992). Cuba, c. 1860-1934. En Bethell, L. (ed.). Historia de América Latina (t.9, pp. 210-239). Barcelona: Crítica.

Cayuela Fernández, J. G. (1998). Un siglo de España: Centenario 1898-1998. Cuenca: Ediciones de la Universidad de Castilla-La Mancha.

de Camps y Feliú, F. (1890). Españoles e insurrectos: Recuerdos de la Guerra de Cuba. La Habana: Imprenta de A. Álvarez y comp.

de Granda, J. (1876). Reflexiones sobre la insurrección de Cuba. Madrid: Imprenta de los Señores Rojas.

Gelpí y Ferro, G. (1879). La regeneración de Cuba y los regeneradores. La Habana: La propaganda Literaria.

Guerra, R. (1952). La Guerra de los Diez Años, 1868-1878. La Habana: Editorial Cultural.

Ibarra Cuesta, J. (2008). Marx y los historiadores: ante la hacienda y la plantación esclavista. La Habana: Editorial de Ciencias Sociales. 
López Oto, E. (1970). La economía cubana durante la Guerra de 1868. Revista de Indias, 30, 403-429.

Moreno Fraginals, M. (1991). Economías y sociedades de plantaciones en el Caribe español, 1860-1930. En Bethell, L. (ed.). Historia de América Latina (t.7, pp. 163-201). Barcelona: Crítica.

Moreno Fraginals, M. (2001). El Ingenio: Complejo económico social cubano del azúcar [ePub]. Madrid: Editorial Crítica.

Pirala, A. (1895-1898). Anales de la Guerra de Cuba. Madrid: Felipe González Rojas Editor.

Roldán, I. (1990). La hacienda en Cuba durante la Guerra de los Diez Años (18681880). Madrid: Instituto de Cooperación Iberoamericana.

Roldán I. (1997). España y Cuba. Cien años de relaciones financieras. Stvdia Histórica. Historia Contemporánea, 15, 35-69.

Soulére, E. (1879). Historia de la insurrección de Cuba (1869-1879). Barcelona: Editorial de Juan Pons.

Varela, F. (1944). Observaciones sobre la constitución política de la monarquía española seguidas de otros trabajos políticos. La Habana: Universidad de La Habana.

Villaamil, M. C. (1883). Cuba. Su presupuesto de gastos. Madrid: Imprenta de R. Moreno y R. Rojas

(C) 2020 por los autores; licencia no exclusiva otorgada a la revista Estudios económicos. Este artículo es de acceso abierto y distribuido bajo los términos y condiciones de una licencia Atribución-No Comercial 4.0 Internacional (CC BY-NC 4.0) de Creative Commons. Para ver una copia de esta licencia, visite http://creativecommons.org/licenses/by-nc/4.0 
